\title{
alpha ille
}

\author{
Animated Documentary. Annabelle Honess Roe. Houndmills, Basingstoke, Hampshire \\ and New York: Palgrave Macmillan, 2013 (194 pages). ISBN 978-1-137-01745-1.
}

\author{
A Review by Susan Danta, UNSW, Australia
}

Annabelle Honess Roe's Animated Documentary tackles the definition of its object through the analysis of internationally acclaimed documentary animation films and an engagement with key scholarship that has helped to establish this field of study. Honess Roe captures and clearly organises the broad spectrum of scholarly material on the topic in a way that is accessibly informative while offering inspiring examples of some of the most innovative animated documentaries of the past two decades. However, Animated Documentary does more than this; as the first book-length study of the topic, it negotiates the many critical approaches towards developing a unified definition of the animated documentary. This is by no means an easy task, with passionate debate encircling the very notion of the validity of the animated documentary form itself. There has been a history of intense scepticism towards animation as an appropriate (and functional) medium of documentary - a mode that is synonymous with the real. But Honess Roe illustrates the fascinating possibilities of the genre and one of the key findings of the book is that the animated documentary is a fundamentally experimental and innovative mode that constantly challenges our preconceptions of what animation and documentary are meant to be.

In her book, Honess Roe describes animated documentary as "a marriage of opposites, made complicated by different ways of seeing the world. The former conjures up thoughts of comedy, children's entertainment and folkloric fantasies; the latter carries with it the assumptions of seriousness, rhetoric and evidence" (1). However, Honess Roe challenges these assumptions and explores the artistic possibilities at the intersection of the two fields, committing herself to setting out a clear definition of animated documentary. Whereas some scholars recognise the authority of documentary as stemming from its indexical relationship to the real, others such as John Grierson argued that documentary has "never fully upheld these characteristics" and that documentary is itself a "creative treatment of reality" (qtd. in Honess Roe 3). Throughout her book, Honess Roe argues that animated documentary is able to present an "alternate world view" (2) and it is in this space that the form is able to assert an authority over the documentary subject.

Honess Roe's central concern is for animated documentary to be acknowledged as a form in its own right. In her Introduction, she discusses the ontology of animated documentary and obstacles that get in the way of the acceptance of animation as "a viable visual representational strategy for documentary" (27). This is followed by an exploration of the ways in which animation is used in animated documentaries, describing different forms of animated representation coupled with detailed analyses of why animation has been used in 
the documentaries instead of more conventional alternatives (for example, photographs, liveaction footage, archival material). The author critiques the indexical imperative assumed in documentary and presents case by case examples of how animation is able to represent the real through "unreal" means. Citing the example of Winsor McCay's 1918 animated documentary film, The Sinking of the Lusitania, Honess Roe argues that McCay and his audience made "no distinction between live action and animation in terms of their ability to show us reality" (8). Interestingly, nearly a century (and many technological advances) later, critics and audiences struggle more now with the idea of the animated document than they did in 1918. The problem is partly attributed to the way that a distinct language of documentary film has been established over the years, which distinguishes it from other film forms such as animation. Honess Roe does not cite examples of documentary or animated film that exist outside of her animated documentary equation, as it is beyond the scope of her book; she instead draws from scholarly texts that identify the ways in which documentaries are often validated by tropes such as the use of evidential photographs and video footage and, in parallel, how animation became synonymous with fiction, frivolity and children's entertainment. Animation has travelled along a divergent trajectory since the early days of The Sinking of the Lusitania. For some, the two forms of animation and documentary continue to remain conceptually segregated; conversely, Honess Roe aims to present an inclusive yet definitive set of rules to define the hybrid form of animated documentaries:

I would first suggest that an audiovisual work (produced digitally, film, or scratched directly to celluloid) could be considered an animated documentary if it: (i) has been recorded or created frame by frame; (ii) is about the world rather than $a$ world; (iii) has been presented as a documentary by its producers and/or received as a documentary by audiences, festivals or critics. (4; emphasis in original)

In accordance to this set of rules, standout examples of animated documentaries include critically acclaimed feature-length, Waltz with Bashir (Ari Folman, 2008), multiaward-winning His Mother's Voice (Dennis Tupicoff, 1999), and the technically groundbreaking Walking with Dinosaurs (Tim Haines, 1999). Hence, Honess Roe's choice in her book is to target animated films that are positioned within the real and, as such, animated documentaries are theorised against established live-action forms of mainstream documentary. Critics of animated documentary often fall into the trap of holding animation up against live-action film, as if it were a comparatively poorer form of representation than the latter. Honess Roe dismisses this critical position, espousing the virtues of animation over live-action footage as a representative strategy to show how contemporary animated documentaries change the way in which we define cinema. Alan Cholodenko and Lev Manovich argue for a reversal of emphasis such that cinema can be read as having derived from animation and it would have been interesting to take this idea further in her argument. The shift in focus to a broader range of disciplines orbiting the animated documentary field is a welcome introduction in the latter part of the book. This includes an analysis of the theoretical work of comics scholar Scott McCloud in the context of the animated documentary. McCloud has famously stated that the stripped back (abstracted) images amplify meaning "in a way that realistic art can't" (qtd. in Honess Roe 108). Here, Honess Roe touches upon the growing field of study of the relationship between comics and animation.

Honess Roe emphasises that, since the 1990s, the form of animated documentary has flourished and expanded with the development of technology and of cross-disciplinary 
approaches to the medium. Although it is not directly addressed in this book, this artistic development can partly be attributed to the remarkable practice-based research at institutions such as the Royal College of Art (RCA), London and the Victorian College of the Arts, Melbourne, amongst others. The research-oriented nature of these institutions encouraged new ways of defining and using the medium of animation. For example, a large portion of animated documentaries mentioned in the book is created by graduates of RCA (Jonathan Hodgson, Tim Webb, Ruth Lingford and Laurie Hill), an institution that has had a profound influence on a generation of animators. In Australia, leading figures in animation such as Melbourne-based Dennis Tupicoff and the late Sarah Watt (Small Treasures, 1995) also taught and influenced a generation of animators including the Southern Ladies Animation Group. The interest in animated documentaries was fuelled and supported by international events such as DoK-Leipzig in Germany and the International Documentary Festival Amsterdam in Holland, where artists and commissioning editors were able to meet and synthesise ideas. Although Honess Roe's book is not a comprehensive survey of animated documentary works themselves, it provides a great starting point to a viewing list of animated documentary films and will be an invaluable resource for readers who are new to the field.

Honess Roe rightly points out that animated documentaries "are most often made by those who are animators first, documentary makers second" (2). This puts an emphasis on form and process as central concerns of animated documentaries. It is, after all, the mode of documentary that is in question here, not the mode of animation, and perhaps this is why the question of whether or not an animation is a documentary is asked more frequently than whether or not a documentary is an animation. Animation, it seems, is able to be polymorphous in a way that the "sacred" form of documentary is not. One could argue that an example of a documentary-led animation is Walking with Dinosaurs, because of the reverse emphasis in this animated documentary (or documentary animation). The hyper-realistic living, breathing dinosaurs are created to scientific specifications and rely upon "markers of indexicality ... to add authenticity to constructed imagery" (49). There is little evidence here of the metamorphic qualities that are, for animation scholar Paul Wells, so intrinsic to the core of animation itself (115).

It becomes clear, then, that a useful definition of animated documentary must be at once specific and sufficiently flexible to capture the broad range of works that fall into this category. To aid in developing such a definition, Honess Roe draws from Eric Patrick's notion of structures of functionality to define her own categories of animated documentary films (23). She describes three different ways in which animation operates in animated documentaries: mimetic substitution, non-mimetic substitution, and evocation. She writes:

Through mimetic substitution, non-mimetic substitution and evocation, animation responds to the limitations of live-action material. Rather than questioning the viability of knowledge through documentary, animated documentaries offer us an enhanced perspective on reality by presenting the world in a breadth and depth that live-action alone cannot. (26)

This "enhanced perspective on reality" is a unique quality of a medium such as animation - and the way in which this is explored is one of the most compelling aspects of this book. There are infinite ways in which animation is able to enhance reality, experience, memory, and scientific/historical facts. These alternative representative strategies open up the form of animated documentaries to exciting possibilities, a number of which are explored by 
Honess Roe. Animated Documentary focuses in fact on three key modes which are consistent with Honess Roe's categories of functionality: digital realities (mimetic substitution), animated interviews (non-mimetic substitution), and subjective representation and animated memories (evocation). Examples of mimetic substitutions in animated documentaries described in Chapter Two ("Digital Realities") include the hand-painted animation in Sinking of the Louisiana, the hyper-realistic 3D animation in Walking with Dinosaurs, and the rotoscoped animation of Chicago 10 (Brett Morgen, 2007). According to Honess Roe, "the visual appeal of animation in the films described in this chapter can be thought of as provoking a desire to know about the film's subject matter" (69). Chapter Three ("Animated Interviews") identifies examples of non-mimetic substitution, including Aardman's muchloved stop-motion production Creature Comforts (Nick Park, 1989) and the mixed-media collaborative project It's Like That (Southern Ladies Animation Group, 2003). These films redefine the "talking-head" animation by substituting real interviewees with their animated interpretations; the result is a "deferral of image to sound" (78). Honess Roe discusses Steven Connor's notion of the vocalic body, which is a "surrogate or secondary body" (78) in these animated documentaries, and argues that voices "are produced by bodies, but can also themselves produce bodies" through animation (79). This chapter also offers a discussion of how the form of animation is used to mask the identities of interviewees in politically sensitive projects. Chapter Four ("The World in Here"), then, focuses on animated documentaries that use animation as evocation. These films include the surrealistic 3D animation Ryan (Chris Landreth, 2005), mixed media work Animated Minds (Andy Glynne, 2003) and the animation/live-action hybrid, Feeling My Way (Jonathan Hodgson, 1997). Each of these works visualises an internal mind's eye. According to Honess Roe, "it is through this inarticulable and individual process of evocation and imagination that the animated documentaries discussed here do their most interesting work to convey subjective experiences that are irreducible to language or image" (137).

Animated Documentary is an ambitious book that reminds its reader of the diverse range of creative practices that fall within the parameters of this hybrid form. Innovative and experimental by its very nature, the animated documentary is an unstable and evolving form that continually expands through the application of new technologies and interdisciplinary approaches. Animated documentaries represent "the world rather than $a$ world" (4; emphasis in original), thus enriching our understanding and every-day encounters within our own lived worlds.

\section{Works Cited}

Animated Minds. Dir. Andy Glynne, 2003. Animation short series.

Chicago 10. Dir. Brett Morgen. Consolidated Documentaries, 2007. Animation.

Cholodenko, Alan, ed. The Illusion of Life: Essays on Animation. Sydney: Power Publications, in Association with the Australian Film Commission, Sydney, 1991. Print.

Creature Comforts, Dir. Nick Park. Aardman Animation, 1989. Animation short. 
Feeling My Way. Dir. Jonathan Hodgson. Arts Council of England, 1997. Animation short.

His Mother's Voice. Dir. Dennis Tupicoff, 1997. Animation short.

It's Like That. Dir. Southern Ladies Animation Group, 2003. Animation short.

McCloud, Scott. Understanding Comics. New York: William Morrow Paperbacks, 1993. Print.

Manovich, Lev. The Language of New Media. 1st ed. Cambridge, Mass.: MIT, 2002. Print.

Ryan. Dir. Chris Landreth. Canada Council for the Arts, 2004. Animation short.

Small Treasures. Dir. Sarah Watt. 1995. Animation short.

The Sinking of the Lusitania. Dir. Winsor McCay. Universal Film Manufacturing Company, 1918. Animation short.

Walking with Dinosaurs. Dir. Tim Haines. BBC, 1999. Television.

Waltz with Bashir. Dir. Ari Folman. Sharmill Films, 2008. Animation.

\section{Suggested Citation}

Danta, Susan. "Animated Documentary by Annabelle Honess Roe" Book review. Alphaville: Journal of Film and Screen Media 8 (Winter 2014). Web. ISSN: 2009-4078.

Susan Danta is an award-winning animator and academic. Her creative practice is comprised primarily of animated documentaries including Heirlooms (2010), Mother Tongue (2003) and Driving Home (2000). Susan's films have travelled extensively to international festivals including Annecy International Animation Festival (France), International Short Film Festival Oberhausen (Germany) and Aspen Filmfest (U.S.). She is a $\mathrm{PhD}$ candidate at UNSW's National Institute for Experimental Art (NIEA). 